\title{
Financial Behaviour of Users of Solomo Platforms during the COVID-19 Pandemic
}

\author{
Anna Zaušková ${ }^{1}$, Michal Kubovics ${ }^{1, *}$, and Martin Vanko ${ }^{1}$ \\ ${ }^{1}$ University of Ss. Cyril and Methodius in Trnava, Faculty of Mass Media Communication, Nam. J. \\ Herdu 2, Trnava 917 01, Slovak Republic
}

\begin{abstract}
.
Research background: COVID-19 has changed the world and the coronavirus crisis has influenced not only undertakings, but also consumers. There is no doubt that this outbreak has reflected on various economic indexes - economic downturn, higher unemployment rate or governments obliged to flexibly face the crisis and trying to tackle the situation. Financial market indicators or financial statements forecast either a certain stagnation or even a dramatic slump. A consumer has thus become the centre of attention because they are expected to have already adapted a certain form of financial behaviour. Behavioural economics is linked to specific methods and indicators that need to be used for evaluating consumers' current financial situation. At the same time, it is important to place emphasis on world globalisation connected with online world and mobile devices. We must admit that mobile consumers are permanently surrounded by social media and customised location modules.

Purpose of the article: The purpose of this article is to study the state of financial behaviour in the domestic environment and e-commerce potential under the most severe COVID-19 preventive measures while comparing the findings with other countries.

Methods: In the quantitative research, comparing the results and searching for correlations between the domestic research sample and the selected EU countries, USA and Asia and individual financial situation and indebtedness of households. The qualitative part of the research consists of theoretical background and secondary sources.

Findings \& Value added: Defining financial behaviour will help corporations get adapted to the current situation. The conclusions we have obtained from our findings can be applied across various business segments.
\end{abstract}

Keywords: globalization; financial; companies in COVID-19; COVID-19 situation; financial behaviour; SoLoMo

JEL Classification: $G 51$; $G 53, M 31$

\footnotetext{
${ }^{*}$ Corresponding author: michal.kubovics@student.ucm.sk
} 


\section{Introduction}

We are currently going through great changes. COVID-19 has become an everyday issue. Governments are implementing preventive measures. Economic downturn is more than inevitable. A new coronavirus has completely hit the world we live in and has changed habits in each sphere of our lives. SoLoMo platforms have not been omitted either. The time we spend online during the pandemic has increased considerably. [1] Consequently, countries have had to react promptly and have implemented various measures in a global scale. People's behaviour has also changed and differentiated. Slovakia has also enforced extensive regulations that triggered hatred and revolt, such as social distancing among people situated at the same time and place. There is no doubt that such a huge impact on people's life will certainly lead to other behavioural changes on various levels. The main objective of this paper is to define the current financial behaviour of Slovak people and compare it with other selected countries.

SoLoMo platforms cover three aspects. They focus on social interaction in the digital environment - the aspect So. Platforms have an endemic character as they are situated within a specific territory - local, the aspect Lo. Platforms focusing on smaller flexible portable devices of a mobile character - the aspect Mo. All indices about their usability suggest that the future lies in the concept divided into particular aspects that are adapted to a certain task or use their full potential by creating a synergic effect from all elements. Changes of behaviour, education or business potential are obvious. The concept is variable and may be adjusted across all segments. SoLoMo platforms have become an ideal medium for any information to be communicated between a recipient and a sender. [2] As for digital devices using SoLoMo platforms, the online environment providing extensive opportunities has become an inseparable part of the whole process. Gao et al. deals with the online environment during the pandemic. They found out e-commerce had grown much stronger during the pandemic times thanks to online shopping. The situation required adaptation and up to a half of respondents admitted buying groceries online. Gao assumes that this behaviour may turn into a habit which will survive the pandemic. [3] In general, behaviour can be difficult to embrace and measure because there are lots of elements coming from both the external and internal environment. The financial situation of individuals and households heavily depend on the economic situation in the country. This is often referred to as macro-environment and micro-environment. Behaviour is often studied from the viewpoint of demographic data and economic indices. [4] Financial behaviour, which is a resultant of various variables, is often influenced by financial literacy as well. A lot of research showed that financial literacy was rather low in the studied target groups. In order to measure financial literacy, Dwon and Xiaom developed a complex scale which was psychometrically verified. It includes three dimensions and these are savings, investments, cash management and loan management. Socalled financial capability is also noteworthy. Financial capability can be assessed by two aspects, i.e. defining behaviour and measuring results and financial behaviour.[5] Bapat states that financial literacy, financial knowledge, financial education and financial capability are often misrepresented in the literature. Financial knowledge can be divided into two categories, subjective knowledge referring to evaluation and customer's objective evaluation dealing with exact data.

Subjective knowledge refers to belief in a certain piece of information while objective knowledge is linked to an individual. [6] The research shows that the low level of financial literacy is directly related to poor financial results of households. The studies suggest that business and economic education at university directly influences final financial behaviour and promotes positive decision-making. Financial behaviour can also be modified by ordinary agents, such as age, gender and various life situations and events, such as establishing a family. [7] According to Morgan and Long, financial security is worth 
considering as well. Having sufficient financial security will positively influence savings, investments in education or business and high-quality health care. Surveys show a direct connection between financial literacy and use of financial services, participation in financial markets as well as voluntary savings. [8] Aydin and Selcuk studied a younger target group of students where the balance sheets indicate suggest that a higher score in financial knowledge directly influences financial attitudes and eventually results in a positive financial behaviour. Besides financial literacy, the final results may also be influenced by various socio-demographic variables as well as the whole range of adjustable and non-adjustable elements. Due to this fact, financial literacy can be defined as a multi-dimensional construct composed of financial knowledge, attitudes and behaviour. [9] Feng et al. speaks about a number of studies dealing with a broad spectrum of variables having an impact on financial behaviour and financial literacy. They refer to an older target group represented by the elderly and people with lower education showing insufficient financial literacy as well as bad habits as part of their financial behaviour. [10] For the last ten years, not only the number but also the complexity of financial products has rapidly increased with people wishing to take control of their financial decisions. As a result, it is important to boost average financial literacy across all levels of education. According to Cucinelli, a geographical location has a huge impact on financial literacy as well as financial behaviour. There are lots of variables that are permanently influenced by the above factors. [11] As for SoLoMo, it is important to point out that finance has also become part of a digital world. Digital functions are multispectral, e.g. they enable payments, communicate the latest financial offers, provide quick investments and ensure mobile payments. On the other hand, these services may penetrate into smaller geographical locations grouping people and helping households with their budgets. Certain parallels with the SoLoMo concept are noticeable. At first, there are mobile applications used by a broad spectrum of people with the numbers expected to rise in the future. [12] Social interaction used to be described as a part of the offline environment. However, social interaction is gradually moving into the online environment, thus meeting the financial behaviour aspects of the SoLoMo concept because social interaction is done through mobile devices, location services and technologies. [13]

\section{Methodology}

The paper is aiming at clarifying the current perception of financial behaviour during the COVID-19 pandemic. The quantitative data were obtained from primary sources, namely evaluation of the questionnaire, and secondary sources, i.e. statistics of research agencies and companies. The data were collected from May 21, 2020 and June 3, 2020 through an online questionnaire with 10 questions. First two questions contained basic respondents' data. The respondents were asked to state their gender and age. The questions analysed possible changes and abnormalities having been caused by generation gaps or a different gender. The following three questions focused on the current attitude to online shopping. The first question was defined as: "Are you doing online shopping more often these days?" and the respondents could select from the answers according to Likert scale: "Certainly", "Yes", "Maybe", "No", "Definitely not". It is an ordinal variable defining respondent's impressions. The following question was: "How may times did you do online shopping last month?" It was a multiple choice questions with the answers 0 , one time, five times, ten times and more: (complete the answer). The question was asked to precise the shopping frequency via a cardinal variable. In order to specify the products, we created categorisation on the basis of the most frequent worldwide categories. [14] In light of the situation that has occurred, the categories we have decided to study are as follows: food, automotive, sport - fitness, electronics, beauty, media and online entertainment. We also added a new category "protective equipment" we considered relevant due to the pandemic. The respondents were 
supposed to arrange the given categories in a descending order according to their buying preferences on the Internet. There were two more questions about a debit card saying: "Do you own a debit card?" with the answers "Yes" and "No" and a nominal variable involved. The other question was "Did you pay by card more last month than usual?" with the answers "Yes" and "No" with a nominal variable involved and the question "Did you manage to save some money for the previous month?" as a nominal variable with the answers "Yes" and "No". The last question focuses on using financial reserves, especially "Did you have to use your financial reserves last month?" with the answers "Yes" and "No" with a nominal variable included. 823 respondents took part in the research with 818 valid results. There were $47.8 \%$ men (391 respondents) and $52.2 \%$ women (427 respondents). $24.8 \%$ of them were from the Generation Z (18-25 years old) (203 respondents). 25.3\% (207 respondents) were from the Generation Y (26-40 years old) and Generation X (41-55 years old) accounting for 25.2\% (202 respondents) and Baby Boomers (56-80 years old) with $25.2 \%$ (206 respondents). The statistics from the Public Health Authority of the Slovak Republic formed an important part of our analysis because we had to study the limitations having a direct impact on people's financial behaviour. We also needed to study the number of the infected people and death tolls and these values were compared with global statistics. As for the secondary sources, we used the research into financial literacy from the company GFLEC and the National Bank of Slovakia. The research by McKinsey \& Company named "Financial life during the COVID-19 pandemic" is crucial for comparison with other countries. The research was done from June 10, 2020 to June 30, 2020 on the sample population from specific countries (South Africa, Brazil, Canada, Chile, Mexico, USA, China, Indonesia, India, France, Germany, Italy, Spain, Great Britain, Russia, Turkey) with the respondents aged over 18. The main objective was to define the state of financial behaviour in Slovakia and present the potential of e-commerce in the changing external environment under COVID19 measures in our country and in comparison with foreign countries. Based upon the statistics for the previous months, we have obtained the list of results that may serve as a basis for defining research conclusions and outcomes.

The hypotheses were defined and will further be tested among the given variables. We assume a statistical dependence between the respondents' age and financial savings. The following hypotheses were formed from the above assumptions:

P1: We assume a statistical dependence between the respondent's age and financial savings. H0: $A$ and $B$ are in independents. There is no statistical dependence between the respondents' age and the studied field (financial savings) in the given samples.

H1: There is a dependence between A and B. There is a statistical dependence between the respondents' age and the studied field (financial savings) in the given samples.

P2: We assume a statistical dependence between the respondents' age and use of financial reserves in the last month. The following hypotheses can be drawn therefrom:

H0: A and B are in independents. There is no statistical dependence between the respondents' age and the studied field (use of financial reserves in the last month) in the given samples.

H1: There is a dependence between A and B. There is a statistical dependence between the respondents' age and the studied field (use of financial reserves in the last month) in the given samples.

P3: We assume a statistical dependence between the respondents' age and online shopping. The following hypotheses can be drawn therefrom:

H0: A and B are in independents. There is no statistical dependence between the respondents' age and the studied field (online shopping) in the given samples.

H1: There is a dependence between A and B. There is a statistical dependence between the respondents' age and the studied field (online shopping) in the given samples. 
P4: We assume a statistical dependence between the respondents' age and creating a financial reserve. The following hypotheses can be drawn therefrom:

H0: A and B are in independents. There is no statistical dependence between the respondents' age and the studied field (creating a financial reserve) in the given samples.

H1: There is a dependence between A and B. There is a statistical dependence between the respondents' age and the studied field (creating a financial reserve) in the given samples.

We used the Chi-Square Test to statistically verify the hypotheses (Goodness of Fit Test). The above test serves for statistical testing of concurrence between the expected and observed values.

$$
X_{N^{2}}=\sum \frac{\left(x_{i}-e_{i}\right)^{2}}{e_{i}}
$$

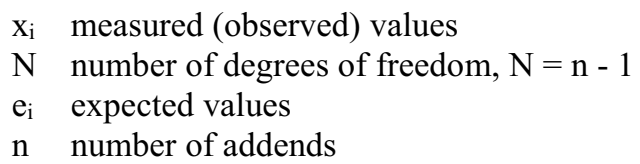

If the value is calculated by the Chi-Square Test, it can be further compared with a critical value corresponding to the selected level of significance $(5 \%)$ in the given number of degrees of freedom.

\section{Results}

After the observations were analysed and clarified, the resultants of values of statistics were demonstrated in the tables of Coronavirus and the appropriate measures were taken. It is essential to study the periods from the point of view of external agents that had occurred prior to respondents' final behaviour. Let's have a look at the year 2020. March 13 - Strict preventive measures were introduced, March 15 - The state of emergency was declared, March 16 - Retail stores were shut down, March 25 - Face masks became obligatory, April 7 - Obligatory quarantine and testing, April 8 - Free movement of people restricted, April 14 End of restrictions on free movement, April 22 - Easing of measures - Phase 1, May 6 Easing of measures - Phase 2 and 3, May 20 - Easing of measures - Phase 4, May 23 to May 29 - eQuarantine, June 3 - Easing of measures - Phase 5. From March 12, 2020 until June 3, 20201,516 patients were tested positive, that is $49.9 \%$ of women and $50.1 \%$ of mean. The highest daily increase was reported on April 14, the day after easing the restrictions on free movement of people (People were allowed to move freely only within their own district). The dramatic decline was observed on April 26, four days after easing the first phase of measures. In total, 26 people died in Slovakia. [15] In comparison with worldwide statistics, the highest number of cases was reported in the North America - 6.33 million. No extremes were observed in the analysis. In general, the number of cases was growing linearly. [16] Conclusions drawn from the analysis point out to some interesting findings. These findings can help us change our behaviour. Financial literacy is one of the most fundamental parts of people's decision-making or their financial behaviour. According to the research by GFLEC, Slovakia occupied the $26^{\text {th }}$ place in the chart of financial literacy. $48 \%$ of adults were found financially literate. On the contrary, the research into the Slovak environment carried out by the company 2 muse on the sample of 1,454 respondents showed that up to $80 \%$ of people were found grammatically literate. Despite these figures, the level of financial literacy is still rather low. [17] A financial reserve is another field that is worth analysing. In their project 
named Household Finance and Consumption Survey (HFCS), the National Bank of Slovakia in cooperation with the Office for Statistics of the Slovak Republic collected data about financial reserves of Slovak households. [18] According to the findings, up to $10 \%$ of Slovak households had no financial reserve before the coronavirus outbreak, while $20 \%$ of households had only a one-month reserve and a half of Slovak households had a six-month reserve. As far as the badly affected sectors are concerned, in the field of trade, services and craft, only $30 \%$ had a one-month reserve and $60 \%$ had a six-month reserve. [19]

Table 1. Question - Do you build a financial reserve regularly?

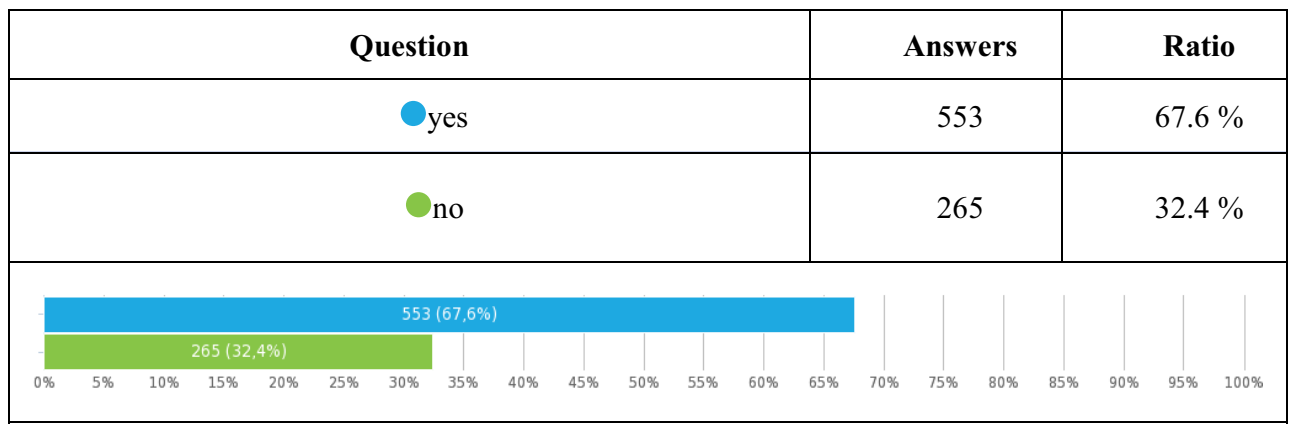

P3: We tested a statistical dependence between the respondents' age and a financial reserve: the tested hypothesis was rejected on its level of significance $\alpha(0.05)$ if the value of a testing criterium exceeds a critical value. The test showed that the age was a determining factor influencing financial savings. The research we carried out in Slovakia demonstrated that $67.6 \%$ (553) of respondents built a proper financial reserve. On the other hand, 32.4\% (265) of respondents did not. According to the findings, we may assume that there are still many respondents who do not systematically save money or do not have to save at all. The above mentioned behaviour may eventually lead to financial destabilisation in the crisis due to failure to satisfy claims and inability to pay ordinary expenses. The survey by McKinsey \& Company named "Financial Life During the COVID-19 Pandemic", carried out from June 10, 2020 to one 30,2020 on the research sample of 18 year olds coming from different countries showed that despite reporting lower income and savings in the research period, such a decline had been lower that the one reported in the previous month. [20]

Table 2. Question - Did you have to use your financial reserves last month?

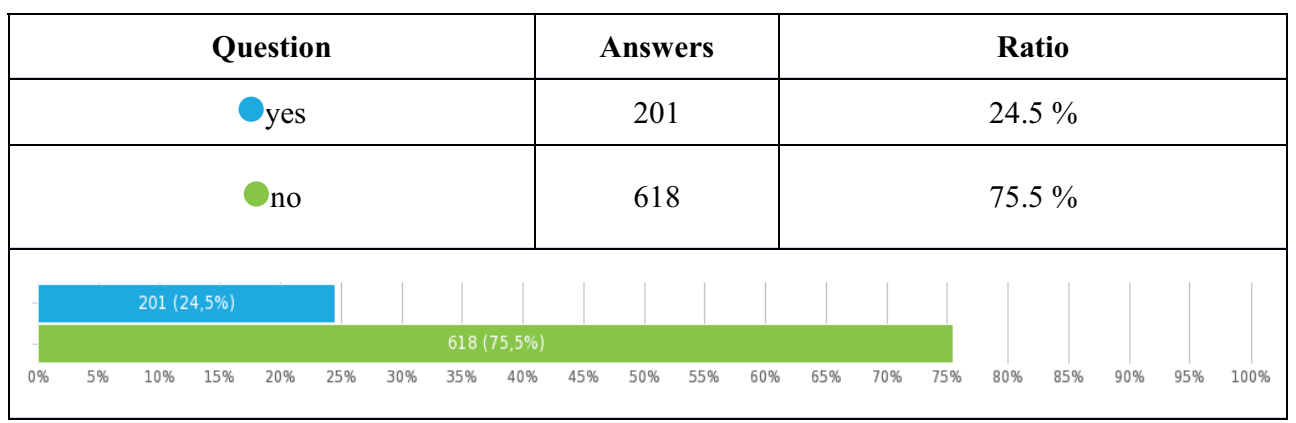

P4: We tested a statistical dependence between the respondents' age and use of a financial reserve in the previous month: The tested hypothesis was rejected on the level of significance $\alpha(0.05)$ if the value of a testing criterium exceeds a critical value. The test demonstrated that the age had a considerable impact on use of a financial reserve in the previous month. 
Table 3. Question - Did you manage to save some money last month?

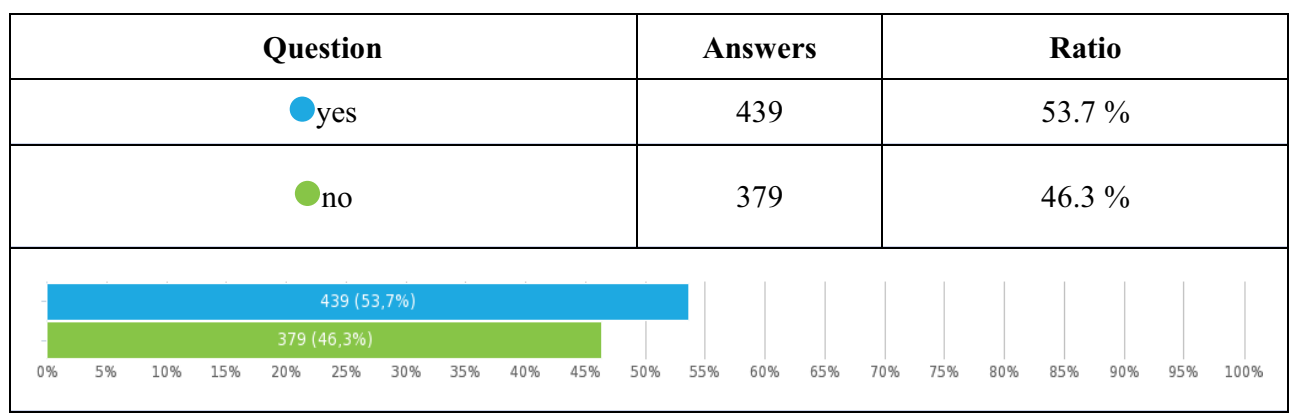

The question was asked to find out whether the respondents had managed to save some money in the previous month. According to the answers, $53.7 \%$ (439) of respondents answered "Yes" and 46.3\% (379) answered "No". The results show that only a half of respondents managed to save money last month while the second half did not. When comparing the results from our research with the survey by McKinsey \& Company, the similar result was obtained. We may confirm that our respondents do far better in contrast to the rest of the world. [18]

P1: We tested a statistical dependence between the respondents' age and savings. The tested hypothesis was rejected on the level of significance $\alpha(0.05)$ if the value of a testing criterium exceeds a critical value. The test demonstrated that the age had a considerable impact on savings.

Digital technologies in the form of smart phones with Internet connection have reported a huge success and covered the majority of population. During the pandemic, smart phones can be used for contactless payments in the same way as a credit card, for instance. The research by McKinsey \& Company showed that cash had been replaced by other payment methods. In comparison with our own research, the respondents' attitude to this question is rather stable. 48.5\% (397) answers "Yes" while 51.5\% (421) answered "No". In contrast to other countries, credit cards were a prevailing payment method. At the same time, mobile and online banking started being extensively used. This behaviour is expected to survive the pandemic times. This habit will change into a platform level and will create a brand new trend of online bank payments or mobile payments.

Table 4. Question - Did you pay by card more last month than usual?

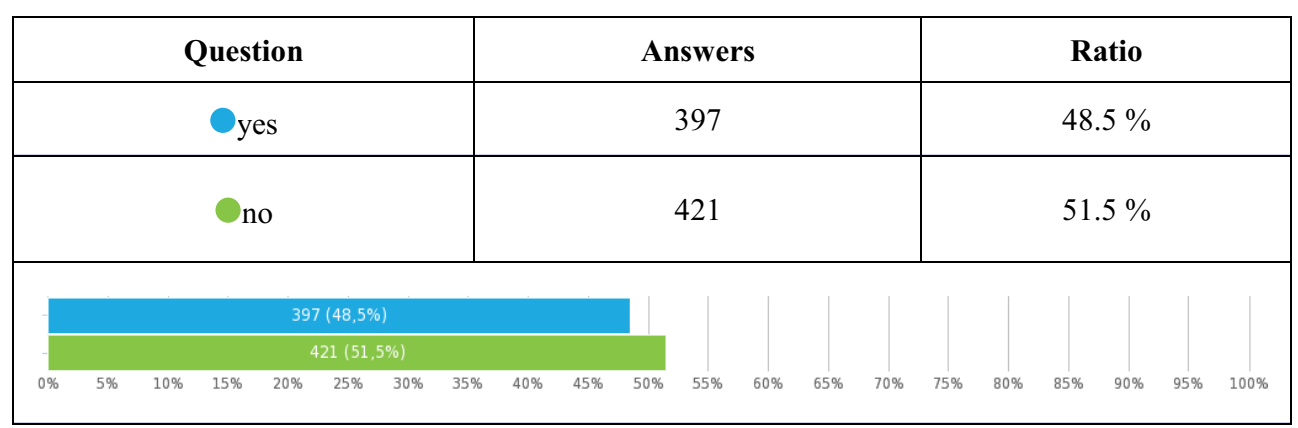

According to the research by Oberlo, a mobile market is globally increasing with further growth to be expected in the future. [21] Based on our research, it is obvious that the respondents' attitude was more negative in the research period and the answer "No" or 
"Certainly not" was prevailing. The Internet sale statistics by the Office for National Statistics of Great Britain reported a considerable growth in the coronavirus pandemic times, i.e. between March and April from 8.2\% to 30.1\%. This number remained stable until July [22].

Table 5. Question - Are you doing more online shopping these days?

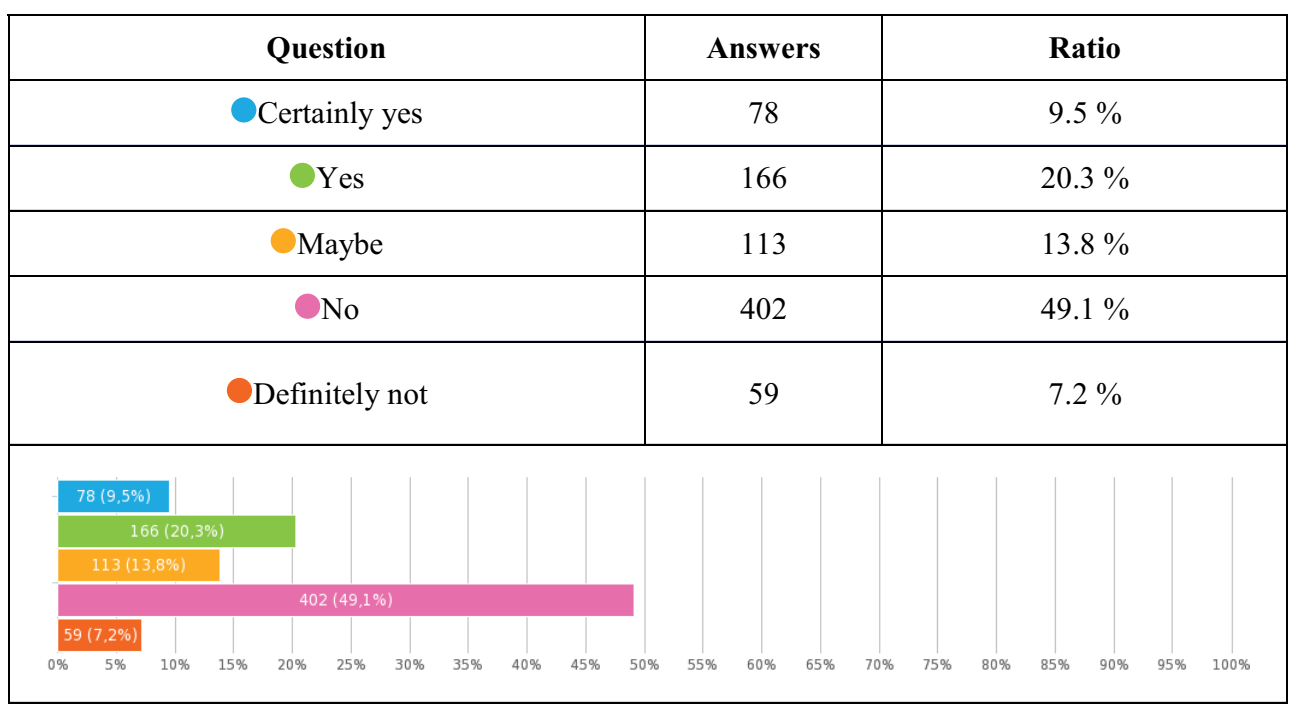

P2: We tested a statistical dependence between the respondents' age and e-shopping between target groups of 18-25 year olds and 26-40 year olds. The tested hypothesis is rejected on the level of significance $\alpha(0.05)$ if the value of a testing criterium exceeds a critical value. The test demonstrated that the age had a considerable impact on e-shopping. The difference among target groups are only minimum.

\section{Discussion and Conclusion}

The paper described the state of financial behaviour in households and e-commerce potential in the changing external environment under the implementation of COVID-19 measures in the home country while comparing these values with foreign countries, which was the main objective of the paper. The values we analysed showed that the situation had been much more favourable in the home environment in contrast to other countries. Most respondents tend to save money on a regular basis. Therefore, we came to the conclusion that this was a sign of proper financial literacy. We also tested the statistical dependence between the respondents' age and creating a financial reserve and found out that the age influenced the saving manners. The main difference may be observed in the age group of 18-25 year olds where $59.1 \%$ of respondents answered "Yes" (83). This was followed by the age group of 26-40 year olds answering "Yes" in 71.5\% of cases (148). As for the age group of 41-55 year olds, the answer "Yes" accounted for 63.9\% (129) and the highest proportion was observed in the age group of 56-80 year olds with $75.7 \%$ (156). Most respondents did not have to use their financial reserves during the pandemic. From the age group of 18-25 year olds, $82.8 \%$ did not have to use their financial reserves (168 cases) and neither did $68.8 \%$ from the age group of 41-55 year olds (139). We might assume that the lockdown measures did not affect the respondents that much. As for savings last month, we can observe that a half of respondents saved some money while the second half did not. This ratio can be observed in the age group of 18-25 with the proportion of $62.9 \%$ (127 respondents) and $37.4 \%$ (76 respondents). This age group had the highest proportion of positive answers. Age 
groups of 41-55 and 56-80 accounted for around 50\% of positive answers and $50 \%$ of negative answers.

When analysis the results, we also had a look at the frequency of online shopping in Generations Y and Z. The results were quite similar with the "No" answer and "Certainly not" answer accounting for $48.4 \%$ (99) in the age group of 18-25. The age group of 26-40 answered "No" and "Certainly not" in $44.9 \%$ of cases (93). A smaller proportion of respondents do not think they are buying online more often than usual. In comparison with other countries, the results seem to be similar. The research by McKinsey \& Company [18] showed similar results in the remaining countries we tested. Therefore, we may declare that financial behaviour is more or less the same across various countries. Depending on the respondents' age, there are certain discrepancies, yet in other features, we are doing the same or a bit better than other countries. Limits of the research are done by heterogeneity of data and the possibility to observe all aspects and variables affecting financial behaviour. Different habits of different nations cause abnormalities and it is complicated to apply equal measurements and generalise conclusions. In the future, the research should focus on studying variables and applying collection across various time relations in a longitudinal manner.

The contribution is a part of research project VEGA 1/0708/18 named: „, Aspects of use of the SoLoMo marketing concept to enhance awareness of eco-innovations".

\section{References}

1. Zaušková, A., Rezníčková, M. (2020). SoLoMo marketing as a global tool for enhancing awareness of eco-innovations in Slovak business environment. Equilibrium, 15(1), 133-150.

2. Gao, X., Shi, X., Guo, H., Liu, Y. (2020). To buy or not buy food online: The impact of the COVID-19 epidemic on the adoption of e-commerce in China. Plos One, 15(8), 114.

3. Shkvarchuk, L., Slav'yuk, R., Lviv Polytechnic National University. (2019). The financial behavior of households in Ukraine. Journal of Competitiveness, 11(3), 144159.

4. Bapat, D. (2019). Segmenting young adults based on financial management behavior in India. International Journal of Bank Marketing, 38(2), 548-560.

5. Bapat, D. (2020). Antecedents to responsible financial management behavior among young adults: Moderating role of financial risk tolerance. International Journal of Bank Marketing, 38(5), 1177-1194.

6. Haliassos, M., Jansson, T., Karabulut, Y. (2019). Financial literacy externalities. The Review of Financial Studies, 950-989.

7. Morgan, P. J., Long, T. Q. (2020). Financial literacy, financial inclusion, and savings behavior in Laos. Journal of Asian Economics, 68, 101197.

8. Aydin, A. E., Akben Selcuk, E. (2019). An investigation of financial literacy, money ethics and time preferences among college students: A structural equation model. International Journal of Bank Marketing, 37(3), 880-900.

9. Feng, X., Lu, B., Song, X., Ma, S. (2019). Financial literacy and household finances: A Bayesian two-part latent variable modeling approach. Journal of Empirical Finance, $51,119-137$. 
10. Cucinelli, D., Trivellato, P., Zenga, M. (2019). Financial literacy: The role of the local context. Journal of Consumer Affairs, 53(4), 1874-1919.

11. Poór, J., Engle, A.D., Ádám Kovács, Á., Albrychiewicz-Slocinska, A., Caha, Z., Kumpikaite-Valiuniene, V., Horbulák, Z. (2020). Initial findings for labour markets in the Czech Republic, Hungary, Poland and Slovakia. Central European Journal of Labour Law and Personnel Management, 3(1), 46-59.

12. He, J., Li, Q. (2020). Can online social interaction improve the digital finance participation of rural households? China Agricultural Economic Review, 12(2), 295313.

13. Time spent online surges during COVID-19 outbreak IAB UK. (2020, May 04). IAB UK. Retrieved from: https://www.iabuk.com/news-article/time-spent-online-surgesduring-covid-19-outbreak

14. Clement, J. (2020, January 21). Leading online shopping categories worldwide 2018. Statista. Retrieved from: https://www.statista.com/statistics/276846/reach-of-toponline-retail-categories-worldwide/

15. COVID-19 report-SK. (2020, September 20). Retrieved from: https://covid19.nczisk.sk/sk

16. Coronavirus (COVID-19) case-Statistics and research. (2020, September 20). Our World in Data. Retrieved from: https://ourworldindata.org/covid-cases.

17. SITA. (2018, September 20). Finančná gramotnost' Slovákov je podla výsledkov prieskumu nízk - VoFinanciách.sk. Webnoviny.sk. Retrieved from: https://www.webnoviny.sk/vofinanciach/financna-gramotnost-slovakov-je-podlavysledkov-prieskumu-nizka/

18. Klapper, L., Annamaria, L., Oudheusden, P. (2015). Financial literacy around the world: Insights from the standard \& poor's ratings services global financial literacy survey. Responsible Finance Forum. Retrieved from: https://responsiblefinanceforum.org/publications/financial-literacy-around-the-worldinsights-from-the-standard-poors-ratings-services-global-financial-literacy-survey/.

19. Cupák, A., Klacso, J., Šuster, M. (2020, March 28) https://www.nbs.sk/_img/Documen ts/_komentare/AnalytickeKomentare/2020/AK78_Financne_rezervy_dōmacnosti.pdf.

20. Euart, J., Ferreira, N., Gordon, J., Gupta, A., Atakan, H., \& White, O. (2020). Financial life during the COVID-19 pandemi - An update | McKinsey. Retrieved from: https://www.mckinsey.com/industries/financial-services/our-insights/a-global-viewof-financial-life-during-covid-19.

21. Mobile commerce sales in 2020 | oberlo. (2020). Retrieved from: https://www.oberlo.com/statistics/mobile-commerce-sales.

22. Murphy, R. (2020). Internet sales as a percentage of total retail sales (Ratio) (\%) Office for National Statistics. Retrieved from: https://www.ons.gov.uk/businessi ndustryandtrade/retailindustry/timeseries/j4mc/drsi. 